\title{
Evaluation of Cultivar Resistance to Soybean Cyst Nematode with a Quantitative Polymerase Chain Reaction Assay
}

Horacio D. Lopez-Nicora, Department of Plant Pathology, Ohio State University, Columbus 43210; James P. Craig, Department of Plant and Microbial Biology, University of California Berkeley, Berkeley 94720; Xuebiao Gao, Pasteuria Bioscience, Inc. 12085 Research Drive, Suite 185 Alachua, FL 32615; Kris N. Lambert, Department of Crop Science, University of Illinois, Urbana 61801 and Terry L. Niblack, Department of Plant Pathology, Ohio State University, Columbus 43210

\begin{abstract}
Lopez-Nicora, H. D., Craig, J. P., Gao, X., Lambert, K. N., and Niblack, T. L. 2012. Evaluation of cultivar resistance to soybean cyst nematode with a quantitative polymerase chain reaction assay. Plant Dis. 96:1556-1563.

Heterodera glycines, the soybean cyst nematode, is a major pathogen of soybean. Effective management of this pathogen is contingent on the use of resistant cultivars; thus, screening for resistant cultivars is essential. The purpose of this research was to develop a method to assess infection of soybean roots by $H$. glycines with real-time quantitative polymerase chain reaction (qPCR). This method will serve as a prelude to differentiation of resistance levels in soybean cultivars. A reproducible inoculation method was developed by means of a sand column to provide active second-stage juveniles (J2). Two-day-old soybean roots were infested with 0 or $1,000 \mathrm{~J} 2 / \mathrm{ml}$ distilled water per seedling. Twenty-four hours after infestation, the roots were surfacesterilized and genomic DNA (gDNA) was extracted. For the qPCR assay, a primer pair for the single copy gene $\mathrm{HgSNO}$, which codes for a

protein involved in the production of vitamin B6, was selected for $H$. glycines gDNA amplification within soybean roots. Compatible 'Lee 74', incompatible 'Peking', and cultivars with different levels of resistance to $H$. glycines were infested with 0 or $1,000 \mathrm{~J} 2 / \mathrm{ml}$ distilled water per seedling. Twenty-four hours postinfestation, infected seedlings were transplanted into pasteurized soil. Subsequently, they were harvested at $1,7,10,14$, and 21 days postinfestation for gDNA extraction. With the qPCR assay, the time needed to differentiate highly resistant cultivars from the rest was reduced. Quantification of $H$. glycines infection by traditional means (numbers of females produced in 30 days) is a time-consuming practice. This qPCR assay has the potential to replace the traditional Female Index-based screening and improve precision in determining infection levels.
\end{abstract}

Heterodera glycines, the soybean cyst nematode ( $\mathrm{SCN}$ ), is a very important pathogen on soybean in the United States and worldwide $(27,28)$. SCN infestations are responsible for significant losses incurred by soybean growers every year (33-35). The use of soybean varieties resistant to $H$. glycines remains the best-recommended method to reduce the impact of this pathogen on soybean production (27). Screening for soybean varieties with high levels of resistance to the nematode is therefore crucial. However, traditional screening methods rely on visually detecting and counting infective SCN propagules. These methods tend to be tedious and timeconsuming. They are also not amenable to high throughput screening of soybean lines and varieties for resistance to SCN.

Resistance to $H$. glycines is a multigenic, quantitative trait (31). The breeding of soybean cultivars resistant to $H$. glycines and assessment of resistance is therefore problematic (31). Currently, the bioassay to determine soybean cultivar reaction to $H$. glycines takes 28 to 30 days after soil infestation with nematode eggs and/or juveniles, allowing development of females for enumeration. The plants' resistance response, however, takes place before 30 days. The use of a DNA-based molecular method could reduce the amount of time required to differentiate $H$. glycines genomic DNA (gDNA) levels among soybean cultivars differing in $H$. glycines resistance.

As an obligate parasite, $H$. glycines requires a living root to complete its life cycle. Root infection takes place regardless of soybean cultivar resistance $(1,10)$. In a typical incompatible response to $H$. glycines, similar to the hypersensitive reaction, the syncytium degenerates and nematodes cannot develop because of the absence of a functional syncytium $(1,26)$.

Corresponding author: Terry L. Niblack, E-mail: niblack.2@osu.edu

Accepted for publication 15 May 2012.

http://dx.doi.org/10.1094/PDIS-12-11-1083-RE

(C) 2012 The American Phytopathological Society
The cultivar Peking (Plant Introduction [PI] 548402) is resistant to $H$. glycines $\mathrm{HG}$ Type 0 , a population for which the Female Index (FI) $<10$ on all HG Type indicator plants (30; FI values are percentages derived from the results of 30-day bioassays, where FI = [mean number of $H$. glycines females on a test soybean line] / [mean number of females on a standard susceptible line] $\times 100$ ). Five days after infection, the syncytia stop developing and the cells become necrotic in roots of Peking (17). In PI 437654, which is resistant to most $H$. glycines populations, the response to infection and eventual cell death is very similar to that of Peking (29). A second type of cellular response is expressed in PI 88788, which accumulates cisternae and rough endoplasmic reticulum, reducing syncytial function (29). Syncytial nuclei degenerate in roots of plants having both types of $H$. glycines resistance (17). This results in a partial or complete reduction of syncytia development, causing the delayed growth or death of the nematode. In resistant cultivars such as Peking, nematodes rarely reach the $\mathrm{J} 3$ stage, and no adults are observed (11).

Identification of $H$. glycines with the polymerase chain reaction (PCR) opened new possibilities in diagnosis when Subbotin et al. (32) detected $H$. glycines $\mathbf{J} 2$ either alone or in mixtures with different soil inhabiting nematodes or Pratylenchus spp. Madani et al. (21) demonstrated a high correlation between nematode gDNA quantity with real-time quantitative polymerase chain reaction (qPCR) and the counted number of nematodes. Briefly, gDNA was extracted from 1, 5, 30, or 500 second-stage juveniles of Heterodera schachtii and Globodera pallida and the cycle threshold $(\mathrm{Ct})$ values from the real-time qPCR increased as number of nematodes increased in the sample. Mekete et al. (25) developed a onestep multiplex PCR reaction using species-specific primers to simultaneously differentiate three different Pratylenchus spp. Agudelo et al. (3) used qPCR to accurately identify Meloidogyne arenaria from other Meloidogyne spp. in soil samples containing a mixture of different species. Their qPCR assay provided an accurate and sensitive approach to identify single juveniles from soil samples. 
We hypothesized that $H$. glycines gDNA content in resistant cultivars would be lower than in susceptible cultivars, and that a molecular method might be used to differentiate $H$. glycines gDNA levels among soybean cultivars differing in $H$. glycines resistance. The objective of this study therefore was to use real-time qPCR to reduce the time needed to identify resistance levels of soybean cultivars by detecting and quantifying $H$. glycines gDNA within soybean roots.

\section{Materials and Methods}

Two experiments were conducted. In the first one, soybean cultivars Lee 74 and Peking (PI 548402) were selected as compatible and incompatible hosts for $H$. glycines, respectively. The seed for these cultivars was obtained from the United States Department of Agriculture - Agricultural Research Service (USDA, ARS) Soybean Germplasm Collection (Urbana, IL). In the second experiment, soybean cultivars with three different levels of resistance to $H$. glycines HG Type 0 were selected from among entries in the 2009 and 2010 Illinois Soybean Variety Tests (Table 1). Resistance levels were based on previously determined FI values and were defined as highly resistant (FI $<10)$, moderately resistant $(25 \leq \mathrm{FI}$ $<40$ ), and susceptible (FI $\geq 60$ ) (A. L. Colgrove, personal communication). The source of $\mathrm{H}$. glycines resistance for each selected cultivar was PI 88788. Three different soybean cultivars were used to represent each level of resistance.

Seed germination. In order to generate uniform seedlings for infestation with $H$. glycines second-stage juveniles (J2), seeds were germinated as described by Mahalingam et al. (22). Briefly, with their hila facing downward, the seeds were rolled in moist, sterilized germination paper. The seeds were then placed into 1-liter beakers containing $100 \mathrm{ml}$ of tap water to facilitate imbibition and germination. The beakers were covered with plastic wrap with airholes and incubated for $48 \mathrm{~h}$ at $27^{\circ} \mathrm{C}$.

Nematode inoculum and inoculation. $H$. glycines isolate UIUC0, HG Type 0, was grown on the susceptible soybean cultivar Lee 74. The plants were maintained in the greenhouse in 5.7-liter polypropylene pots partially submerged in a $27^{\circ} \mathrm{C}$ water bath under a 16-h photoperiod. Thirty days postinfestation (dpi), mature females were dislodged from the roots with a high pressure water spray. Eggs were released from the females by gentle crushing with a rubber stopper against a $150-\mu \mathrm{m}$-aperture sieve, and collected onto a 25 - $\mu \mathrm{m}$-aperture sieve (8). Eggs were concentrated by sucrose centrifugation (16), and the solution containing eggs was placed on a nylon sieve $(41-\mu \mathrm{m}$-aperture) above a water reservoir for hatching (1). J2 were collected every day from hatching sieves

Table 1. Selected soybean cultivar responses to infection with Heterodera glycines HG Type $0^{\mathrm{a}}$

\begin{tabular}{llccc}
\hline Seed company & Cultivar & FI $^{\mathbf{b}}$ & Rating $^{\mathbf{c}}$ & $\begin{array}{c}\text { Source of } \\
\text { resistance }^{\mathbf{d}}\end{array}$ \\
\hline Wilken & W 2672 NSTS & 0 & HR & PI 88788 \\
Emerge Genetics & XC 3810 & 1 & HR & PI 88788 \\
FS Hisoy & HS 4366 & 1 & HR & PI 88788 \\
Merschman & NASHVILLE 749RR & 27 & MR & PI 88788 \\
G2 (Nutech) & 7438 & 27 & MR & PI 88788 \\
Great Lakes & GL 3259 R2 & 27 & MR & PI 88788 \\
Nutech & 3255 L & 150 & S & PI 88788 \\
Horizon & 30N11 L & 166 & S & PI 88788 \\
Mavrick & 9298 LL & 107 & S & PI 88788 \\
\hline
\end{tabular}

${ }^{a}$ Female indices and resistance ratings were determined during the 2009 and 2010 Illinois Soybean Variety Tests (A. L. Colgrove, personal communication).

${ }^{\mathrm{b}}$ Female Index $(\mathrm{FI})=($ average number of females developed on the test soybean cultivar/average number of females developed on a standard susceptible) $\times 100$ in a bioassay conducted for 30 days in a greenhouse. The $H$. glycines test population was UIUC0, an HG Type 0 .

${ }^{c}$ Resistance level for each cultivar based on the FI: HR = highly resistant, $\mathrm{FI}<10 ; \mathrm{MR}=$ moderately resistant, $\mathrm{FI}>24<40$; and $\mathrm{S}=$ susceptible, FI $>59$.

d Source of resistance to Heterodera glycines as reported by the seed company. until the target inoculum level was reached. Twelve hours before use, $\mathbf{J} 2$ were placed on a sterile sand column above a water reservoir, and the active $\mathrm{J} 2$ were collected at the bottom of the column in sterile distilled water $(9,18)$. The active $\mathrm{J} 2$ were suspended in sterile distilled water at a concentration of $1,000 \mathrm{~J} 2 / \mathrm{ml}$.

In the first experiment, we tested a method to consistently infect soybean seedlings with $\mathrm{J} 2$ and developed a real-time qPCR assay to detect $H$. glycines gDNA in infected soybean roots. Fifteen-cmlong polyvinyl chloride (PVC) tubes were cut in half lengthwise. These tubes were placed horizontally in trays and filled with a steam-pasteurized sandy loam soil, $77 \%$ sand, $11 \%$ silt, $12 \%$ clay, $\mathrm{pH} 7.8$, and $0.9 \%$ organic matter. Uniform 3 - to 5-cm-long soybean seedlings were placed horizontally at one end of each half-tube for infestation. To assess the consistency of our inoculation technique, 10 seedlings each of Lee 74 and Peking were infested with 0 or $1,000 \mathrm{~J} 2 / \mathrm{ml}$ of distilled water per seedling, and treatments were distributed randomly in the inoculation trays. All seedlings were covered with moistened, pasteurized sandy loam soil and incubated horizontally at $27^{\circ} \mathrm{C}$. After $24 \mathrm{~h}$, the seedlings were removed, rinsed, and surface sterilized with $10 \%$ bleach for $30 \mathrm{~s}$. Half the seedlings were frozen at $-20^{\circ} \mathrm{C}$ for gDNA extraction, and the remaining seedlings were stained as described in Byrd et al. (6) for enumeration of $\mathrm{J} 2$ under a stereoscope. This experiment was conducted twice for the real-time qPCR assay and three times for the nematode counts.

For the qPCR assay, 100 seedlings each of Lee 74 and Peking were germinated, selected, and infested as described in the preceding paragraph. At 24-h postinfestation (hpi), all seedlings were washed under running tap water to remove free $\mathrm{J} 2$ that had not infected the seedlings (11). Infected seedlings were transplanted to 5.7-liter polypropylene pots. Each pot contained 22 PVC tubes ( 3 $\mathrm{cm}$ diameter $\times 15 \mathrm{~cm}$ long) filled with $100 \mathrm{~cm}^{3}$ of pasteurized sandy loam soil each. Seedlings were transplanted into each tube $(7,8)$. The plants were maintained in the greenhouse with each pot three-fourths submerged in a $27^{\circ} \mathrm{C}$ water bath under a 16 -h photoperiod until harvested. After 1, 7, 10, 14, and 21 dpi, five each of infested and mock-infested (sterile distilled water) Lee 74 and Peking soybean seedlings were surface sterilized and frozen at $-20^{\circ} \mathrm{C}$ for gDNA extraction and real-time qPCR assay.

For the second experiment, soybean cultivars with different levels of resistance to $H$. glycines were used. Uniform seedlings of nine cultivars with different levels of resistance (Table 1) and Lee 74 (internal susceptible control) were used. Three seedlings of each cultivar were infested with $1,000 \mathrm{~J} 2 / \mathrm{ml}$ of distilled water per seedling as described for the first experiment. Three seedlings (Lee 74) were mock-inoculated with sterile distilled water. At $24 \mathrm{hpi}$, all seedlings were washed and transplanted to inoculum-free pots as described for the first experiment. The infested soybean seedlings were surface-sterilized and frozen at $-20^{\circ} \mathrm{C}$ for gDNA extraction at 7, 10, 14, and 21 dpi.

DNA extraction from nematodes and soybean roots. As nematodes develop, the amount of gDNA should increase. Because resistance derived from PI 88788 reduces male development much less than resistance derived from Peking, the quantity of gDNA in males had to be accounted for. To compare gDNA content in adult males and $\mathbf{J} 2$, nematodes were individually digested as described

Table 2. Primers used for real-time quantitative polymerase chain reaction (qPCR) assays targeting Heterodera glycines and Glycine max

\begin{tabular}{|c|c|c|c|}
\hline Amplicon & $\begin{array}{l}\text { Accession } \\
\text { no. }^{\mathrm{a}}\end{array}$ & Primers $\left(5^{\prime} \rightarrow 3^{\prime}\right)^{b}$ & $\begin{array}{l}\text { Size } \\
(\mathbf{b p})^{\mathrm{c}}\end{array}$ \\
\hline $\mathrm{HgSNO}$ & EU747298 & $\begin{array}{l}\text { F: AGGCAACGTGCAGCAACAT } \\
\text { R: CTGATCGCCAGTCTTCACTATGA }\end{array}$ & 76 \\
\hline Lectin & K00821 & $\begin{array}{l}\text { F: CTTTCTCGCACCAATTGACA } \\
\text { R: TCAAACTCAACAGCGACGAC }\end{array}$ & 102 \\
\hline
\end{tabular}

${ }^{a}$ Primer sequences available through the National Center for Biotechnology Information (NCBI).

${ }^{\mathrm{b}} \mathrm{F}$ and $\mathrm{R}$ indicate forward and reverse primers.

${ }^{\mathrm{c}} \mathrm{bp}=$ base pairs. 
by Craig et al. (9). Briefly, 10 males and $10 \mathrm{~J} 2$ were handpicked and individually digested in $5 \mu$ l buffer $(50 \mathrm{mM}$ Tris- $\mathrm{HCl}, 50 \mathrm{mM}$ $\mathrm{NaCl}, \mathrm{pH} 7.5$ ) containing $4 \mathrm{mg} / \mathrm{ml}$ of protease $\mathrm{K}$ (Invitrogen, Carlsbad, CA). The protease $\mathrm{K}$ was inactivated after $24 \mathrm{~h}$ by incubation at $80^{\circ} \mathrm{C}$ for $30 \mathrm{~min}$. Genomic DNA was further used in qPCR.

DNA was extracted from infected and noninfected roots with the FastDNA SPIN Kit and the FastPrep instrument (MP Biomedicals, Santa Ana, CA) following the manufacturer's manual with modifications as described by Malvick and Grunden (23). J2 infection was observed to occur in the 3 to $5 \mathrm{~cm}$ of root that was originally infested; therefore, roots from which DNA was collected were standardized to $7 \mathrm{~cm}$ length at harvest. Surface-sterilized roots were placed in $2.0 \mathrm{ml}$ of lysing matrix in tubes containing garnet particles and a 6.35-mm ceramic sphere, 1,000 $\mu \mathrm{l}$ of Cell Lysing Solution (CLS-TC) extraction buffer, and $80 \mu$ of polyvinylpyrrolidone solution (PVP in $1 \mathrm{mg} / 10 \mu \mathrm{l}$ stock solution). A second $6.35-\mathrm{mm}$ ceramic bead was added and homogenized twice in the FastPrep instrument for $30 \mathrm{~s}$ at a speed setting of 4.5 in intervals of $5 \mathrm{~min}$. Samples were centrifuged for $7 \mathrm{~min}$ at $11,500 \mathrm{rpm}$. The supernatant was transferred to a new $1.5-\mathrm{ml}$ tube and the same procedure repeated; $600 \mu \mathrm{l}$ of the supernatant was transferred to $1.5-\mathrm{ml}$ tubes containing an equal volume of the binding matrix. From this point onward, steps were followed as described in the manufacturer's protocol. For extraction of gDNA from the J2 suspension, $1 \mathrm{ml}$ of suspended $\mathrm{J} 2$ was pipetted into a lysing tube and the same procedure used for the roots was performed. $H$. glycines gDNA concentrations were measured with a Nano Drop (ND1000 , Thermoscientfic, DE) and stored at $-20^{\circ} \mathrm{C}$.

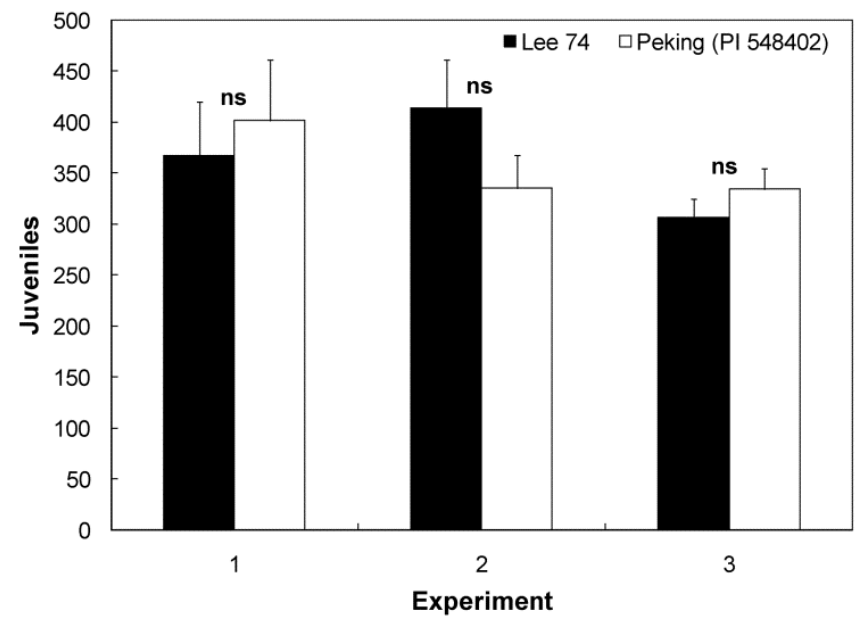

Fig. 1. Number of Heterodera glycines second-stage juveniles (J2) within roots of compatible soybean host cultivar Lee 74 and incompatible cultivar Peking (PI 548402) $24 \mathrm{~h}$ postinfestation with $1,000 \mathrm{~J} 2 / \mathrm{ml}$ of distilled water per seedlings. Nematodes were passed through a sand column to obtain active inoculum. Within each experiment, cultivars followed by 'ns' did not differ at $\alpha=0.05$.
Selection of primers, test for inhibitors and efficiency of the primers. To specifically detect $H$. glycines gDNA, a primer pair amplifying the single-copy nematode gene $\mathrm{HgSNO}$ was selected (9). To detect soybean genomic DNA and verify successful DNA extraction from the infected and noninfected roots, a primer pair amplifying a soybean lectin gene was selected (4) (Table 2).

The efficiency of the $\mathrm{HgSNO}$ primer pair was tested as described in Livak and Schmittgen (20). Briefly, qPCR was performed on a 10 -fold dilution series starting with $89.6 \mathrm{ng}$ of $H$. glycines gDNA, and the $\Delta \mathrm{Ct}$ was calculated between each dilution. The efficiency of the primers was evaluated by observation of $\Delta \mathrm{Ct}$ for each $10-$ fold dilution.

To test for PCR inhibitors in the DNA extracted from soybean roots, five 10-fold dilutions of soybean gDNA was prepared starting at $71 \mathrm{ng} / \mu \mathrm{l}$. Each dilution was mixed in a 1:1 ratio with 7.8 $\mathrm{ng} / \mu \mathrm{l}$ of $H$. glycines gDNA. QPCR was performed to amplify $H g S N O$ from the dilution series spiked with $H$. glycines gDNA.

Real-time qPCR assay. The SYBR Green real-time qPCR assay was conducted on an ABI PRISM 7000 sequence detection system instrument (PE Applied Biosystems, Foster City, CA). The amplification reactions were performed on a 96-well Optical Reaction Plate with a $25-\mu \mathrm{l}$ reaction volume. Reaction mixtures contained $12.5 \mu \mathrm{l}$ of SYBR Green PCR Master Mix (Applied Biosystems), $0.25 \mu \mathrm{l}$ of each 5 pmoles of $\mathrm{HgSNO}$ and Lectin primers, $5 \mu \mathrm{l}$ of template DNA, and $7.25 \mu \mathrm{l}$ of sterile distilled water. The reaction cycles were: preincubation at $50^{\circ} \mathrm{C}$ for $2 \mathrm{~min} ; 95^{\circ} \mathrm{C}$ for 10 min; 40 cycles of $95^{\circ} \mathrm{C}$ for $15 \mathrm{~s}$ each, and $60^{\circ} \mathrm{C}$ for $1 \mathrm{~min}$, dissociation stage.

Duplicates or triplicates of each reaction were run on each plate. Analysis was based on absolute quantification generating amplification curves for each reaction with $\mathrm{ABI}$ sequence detection software. Cycle threshold $(\mathrm{Ct})$ values were calculated with the automatic baseline analysis option (21).

Statistical analysis. Each experiment consisted of completely randomized tubes in the inoculation tray. Treatments were the cultivar-inoculation combinations. Analysis of variance (ANOVA) was conducted with the MIXED procedure in SAS (Version 9.2, SAS Institute, Cary, NC). Effects were considered significant at $P$ $\leq 0.05$. The UNIVARIATE procedure was used to verify the normality of the residuals. Homoscedasticity was checked with the GLM (general linear models) procedure with the MEANS statement on the residuals. Brown and Forsythe's HOVTEST option was used to compute statistics to test for the homogeneity of variance assumption.

\section{Results}

Root infection. Active J2 produced consistent infection (Fig. 1). Stained nematodes inside infected seedlings were counted at 24 hpi. Infection of Lee 74 (compatible) and Peking (incompatible) did not differ within each experiment (Table 3), and this result was consistent among all three experimental repetitions (Table 3 ). The percentage of infection in both compatible and incompatible hosts within 24 hpi ranged from 31 to $41 \%$. The mean

Table 3. Penetration of compatible soybean cultivar Lee 74 and incompatible cultivar Peking (PI 548402) by Heterodera glycines second-stage juveniles (J2) $24 \mathrm{~h}$ postinfestation with $1,000 \mathrm{~J} 2 / \mathrm{ml}$ of distilled water per seedling

\begin{tabular}{|c|c|c|c|c|c|c|}
\hline \multirow[b]{2}{*}{ Experiment $^{\mathbf{b}}$} & \multirow[b]{2}{*}{ Host } & \multicolumn{5}{|c|}{ Juveniles $^{\mathbf{a}}$} \\
\hline & & Range & Mean (no.) & Infection (\%) & $P$ & Pooled $P^{c}$ \\
\hline \multirow[t]{2}{*}{1} & Lee 74 & $235-553$ & 366 & 37 & 0.677 & \\
\hline & Peking & $221-589$ & 401 & 40 & & \\
\hline \multirow[t]{2}{*}{2} & Lee 74 & $300-580$ & 413 & 41 & 0.213 & 0.272 \\
\hline & Peking & $244-415$ & 335 & 34 & & \\
\hline \multirow[t]{2}{*}{3} & Lee 74 & $255-350$ & 306 & 31 & 0.345 & \\
\hline & Peking & $280-398$ & 334 & 33 & & \\
\hline
\end{tabular}

${ }^{a}$ Infected seedlings were stained with acid fuchsin (7) and nematodes were counted with a stereoscope at $\times 64$ magnification. Range, mean, and infection rate represent five replications for each cultivar within an experiment.

${ }^{\mathrm{b}}$ In each experiment, five seedlings each of Lee 74 and Peking were infested with $H$. glycines $\mathrm{J} 2$, collected after being allowed to crawl through a column of sterilized sand.

c $P$ value for three experiments when pooled. 
number of $\mathrm{J} 2$ penetrating the seedlings ranged from 306 to 401/seedling (Table 3).

Sensitivity and efficiency of primers for $\mathrm{HgSNO}$ and inhibitors tests. The primer pair for $H g S N O$ detected, amplified, and quantified $H$. glycines gDNA from infected Lee 74 and Peking soybean seedlings, and from pure J2 DNA. However, there was no amplification of $H$. glycines gDNA from noninfected seedlings or sterile distilled water. The lowest $H$. glycines gDNA concentration detected and quantified on a 10 -fold dilution series was $89.6 \times 10^{-5}$ $\mathrm{ng} / \mu \mathrm{l}$ with an average $\mathrm{Ct}$ value of 32.72 (data not shown). Primer efficiency for the real-time qPCR was determined by comparison of the $\Delta \mathrm{Ct}$ of serial 10-fold dilutions of the gDNA. The highest $H$.

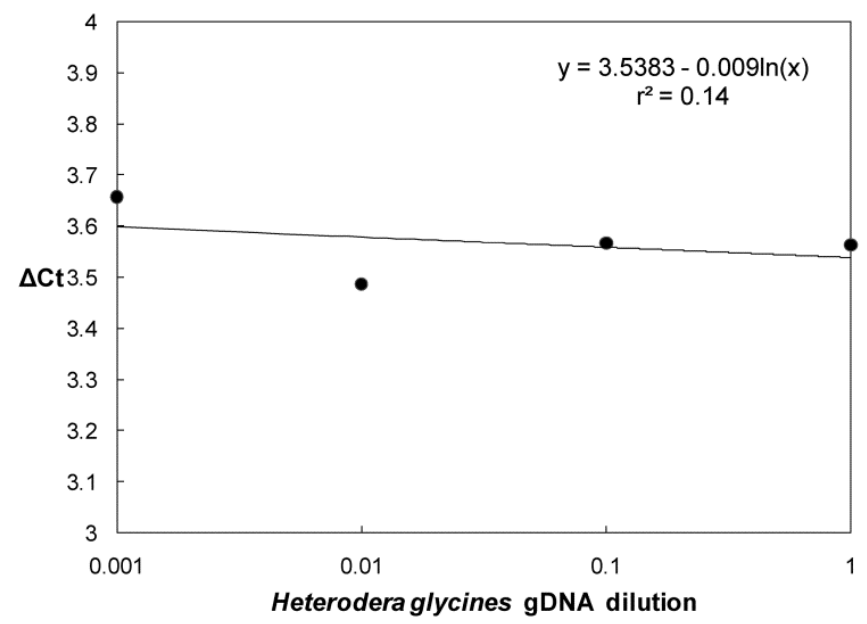

Fig. 2. Differences in cycle threshold $(\Delta C t)$ values with SYBR Green real-time quantitative polymerase chain reaction (qPCR) and analysis of the efficiency of a primer pair for the Heterodera glycines gene HgSNO tested with a 10-fold serial dilution of genomic $H$. glycines DNA starting at $89.6 \mathrm{ng} / \mu \mathrm{l}$. glycines gDNA concentration was $89.6 \mathrm{ng} / \mu \mathrm{l}$. The $\Delta \mathrm{Ct}$ between dilutions were similar, ranging from 3.49 to 3.66 (Fig. 2).

To test the qPCR assay for inhibition from soybean roots, 7.8 $\mathrm{ng} / \mu \mathrm{l}$ of $H$. glycines gDNA was mixed in a 1:1 ratio with $71,7.1$, $0.71,0.071,0.0071$, and $0.00071 \mathrm{ng} / \mu \mathrm{l}$ of soybean gDNA. The results demonstrated that the $H$. glycines gDNA amplification at each soybean gDNA concentration was not different $(P=0.637)$ (Fig. 3). This indicated that there was no inhibition in the presence of soybean gDNA.

Real-time qPCR assay. The results obtained with the SYBR Green real-time qPCR assay matched with the results of nematodes counted in stained, infected roots. The content of $H$. glycines gDNA in Lee 74 and Peking roots did not differ within or between experiments (Table 4). Amplification plots for real-time qPCR showed a tight band of amplified reactions (Fig. 4). The means of qPCR Ct values were compared for Lee 74 and Peking within each experiment, and a $\Delta \mathrm{Ct}$ was calculated (Table 4). The range of $\mathrm{Ct}$ values was similar between the first experiment ( $\mathrm{Ct}$ values 22.25 to 25.40 ) and the second ( $\mathrm{Ct}$ values 22.38 to 24.88). An endogenous control for the soybean lectin gene was used to verify successful DNA extraction. Amplification and quantification of the lectin gene was observed in every reaction where amplification of $H$. glycines gDNA was recorded, with $\mathrm{Ct}$ values ranging from 17.67 to 35.80 (data not shown).

Genomic DNA content in male versus second-stage juvenile. The results obtained with the SYBR Green real-time qPCR assay showed that the content of gDNA in fully developed males differed $(P \leq 0.001)$ from gDNA content of $\mathrm{J} 2$ (Fig. 5). Mean average $\mathrm{Ct}$ values for 10 digested males was 25.3 compared with a mean $\mathrm{Ct}$ value of 23.3 for the same number of $\mathrm{J} 2$. The $\Delta \mathrm{Ct}$ value between an adult male $H$. glycines and a $\mathrm{J} 2$ was 2 , which indicated a fourfold greater gDNA content in males than in $\mathrm{J} 2$.

Genomic DNA content in Lee 74 versus Peking (PI 548402). H. glycines gDNA content in compatible host Lee 74 and incompatible Peking was compared at different dpi with SYBR Green

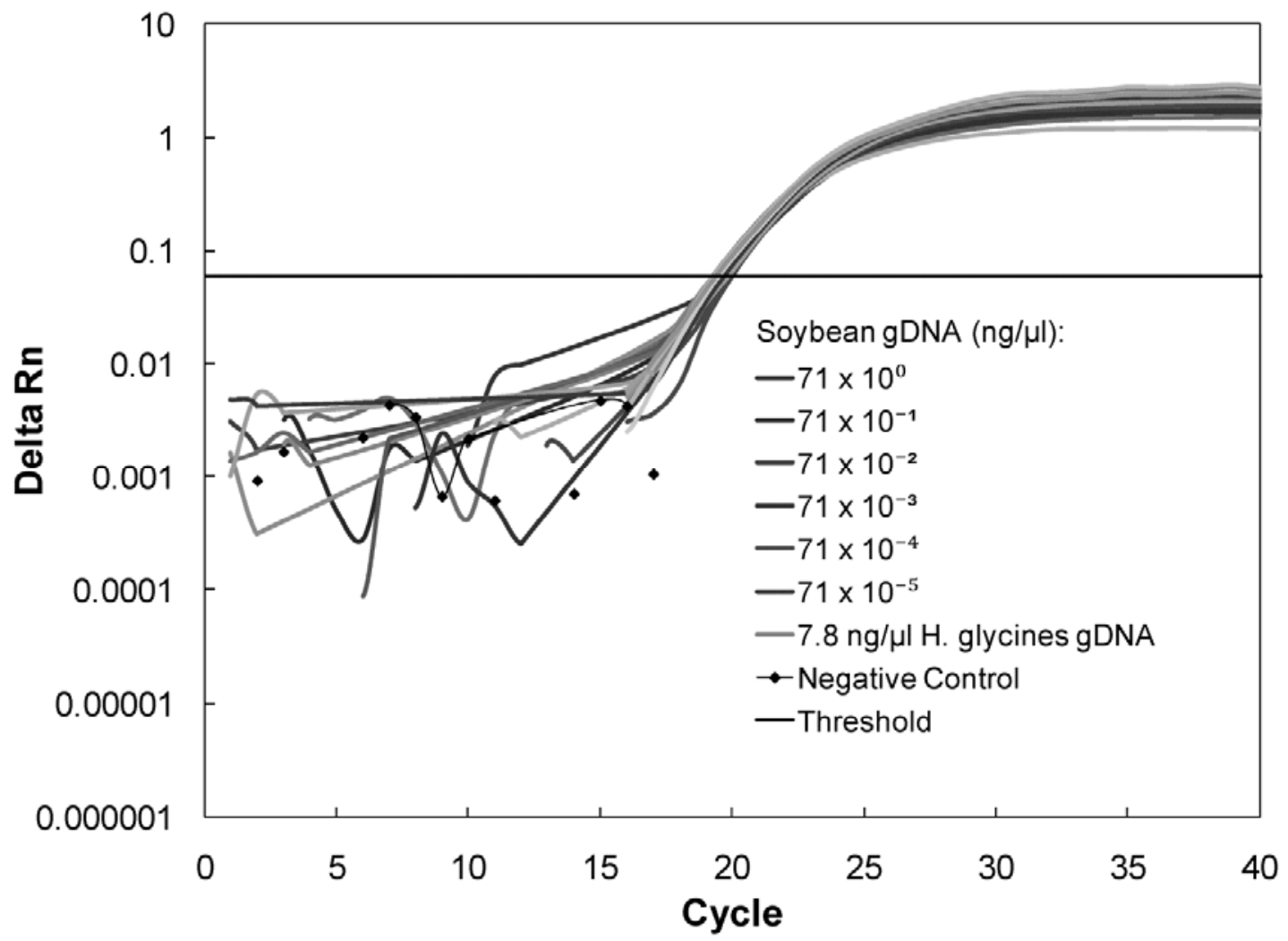

Fig. 3. Amplification plot of Heterodera glycines genomic DNA in a SYBR Green real-time quantitative polymerase chain reaction (qPCR) with a primer pair designed to amplify the nematode $\mathrm{HgSNO}$ gene in serially diluted soybean genomic DNA combined in a 1:1 mixture with $7.8 \mathrm{ng} / \mathrm{\mu l} \mathrm{H}$. glycines genomic DNA. Distilled water was used in place of DNA for a negative control. 
real-time qPCR (Table 5). At 10 and 21 dpi, Peking had less $H$. glycines gDNA than Lee 74, as demonstrated by the higher $\mathrm{Ct}$ values. $H$. glycines gDNA in Lee 74 and Peking did not differ at 1 and $14 \mathrm{dpi}$. The same results were obtained when this experiment was repeated (Table 5). At $7 \mathrm{dpi}$, however, results were inconsistent. In experiment one, $H$. glycines gDNA content in Lee 74 and Peking did not differ. In experiment two, on the other hand, gDNA content in Lee 74 differed from that of Peking (Table 5).

Soybean cultivars with different levels of resistance to $\mathrm{H}$. glycines. $H$. glycines gDNA content was compared at 7, 10, 14, and 21 dpi with SYBR Green real-time qPCR in three highly resistant, three moderately resistant, and three susceptible soybean cultivars as well as cultivar Lee 74 (Table 6). The source of resistance for all nine cultivars was PI 88788, and Lee 74 was the susceptible check. Cultivars with the same FI values were pooled, and the mean $\mathrm{Ct}$ values were calculated. Single-degree-of-freedom contrasts were performed for each harvest point. Results from the two experimental repetitions were similar only at 10 and $21 \mathrm{dpi}$ (Table 6). At $10 \mathrm{dpi}, H$. glycines gDNA content in highly resistant, moderately resistant, susceptible, and cultivar Lee 74 differed from each other. However, at $21 \mathrm{dpi}, H$. glycines gDNA content in cultivars with high resistance and that in those with moderate resistance did not differ. Likewise, $H$. glycines gDNA content in Lee 74 did not differ from that in susceptible cultivars (Table 6).

\section{Discussion}

This study successfully developed a qPCR assay to detect differences in $H$. glycines gDNA content between compatible and incompatible hosts at 10 dpi. Likewise, differences between highly resistant, moderately resistant, and susceptible cultivars were observed $10 \mathrm{dpi}$, reducing by 20 days the time needed to distinguish these cultivars using traditional FI-based screening.

Incorporation of a sand column in the inoculation technique reduced the variation of $\mathbf{J} 2$ penetration into seedlings. Variable rates of penetration have been a problem in similar studies $(2,7,15,22)$. Due to variability in the hatching rate, collecting J2 until the desired inoculum level is reached takes time, and results in inoculum of different ages and viability. Mahalingam et al. (22) noticed that

Table 4. Comparison of Heterodera glycines genomic DNA (gDNA) content in compatible soybean cultivar Lee 74 and incompatible cultivar Peking (PI 548402) $24 \mathrm{~h}$ postinfestation with 1,000 H. glycines second-stage juveniles (J2)/ml of distilled water per seedling based on a SYBR Green real-time quantitative polymerase chain reaction (qPCR) assay with a primer pair designed to amplify the $H g S N O$ gene in $H$. glycines

\begin{tabular}{|c|c|c|c|c|c|c|c|}
\hline \multirow[b]{2}{*}{ Experiment $^{\mathbf{b}}$} & \multicolumn{2}{|c|}{ Average qPCR Ct value ${ }^{a}$} & \multirow[b]{2}{*}{$\mathbf{S D}^{\mathbf{c}}$} & \multirow[b]{2}{*}{$\Delta \mathbf{C t}$} & \multirow[b]{2}{*}{$2^{-\Delta C t d}$} & \multirow[b]{2}{*}{$P$} & \multirow[b]{2}{*}{ Pooled $P$ e } \\
\hline & Lee 74 & Peking & & & & & \\
\hline 1 & 23.33 & 22.84 & 0.585 & -0.49 & 1.40 & 0.426 & 0.065 \\
\hline 2 & 24.16 & 23.53 & 0.501 & -0.63 & 1.55 & 0.243 & \\
\hline
\end{tabular}

${ }^{a}$ Genomic DNA extracted from infected soybean roots was amplified and quantified with primers for $H g S N O$. The cycle threshold (Ct) values were averaged. $\mathrm{Ct}=$ threshold cycle number when fluorescence of the sample exceeded background fluorescence.

${ }^{\mathrm{b}}$ Each experiment comprised five replications per soybean cultivar.

${ }^{\mathrm{c}} \mathrm{SD}=$ standard deviation.

d $2^{-\Delta \mathrm{Ct}}$ represents the fold difference in gDNA content between cultivar Lee 74 and cultivar Peking (PI 548402).

e $P$ value for three experiments when pooled.

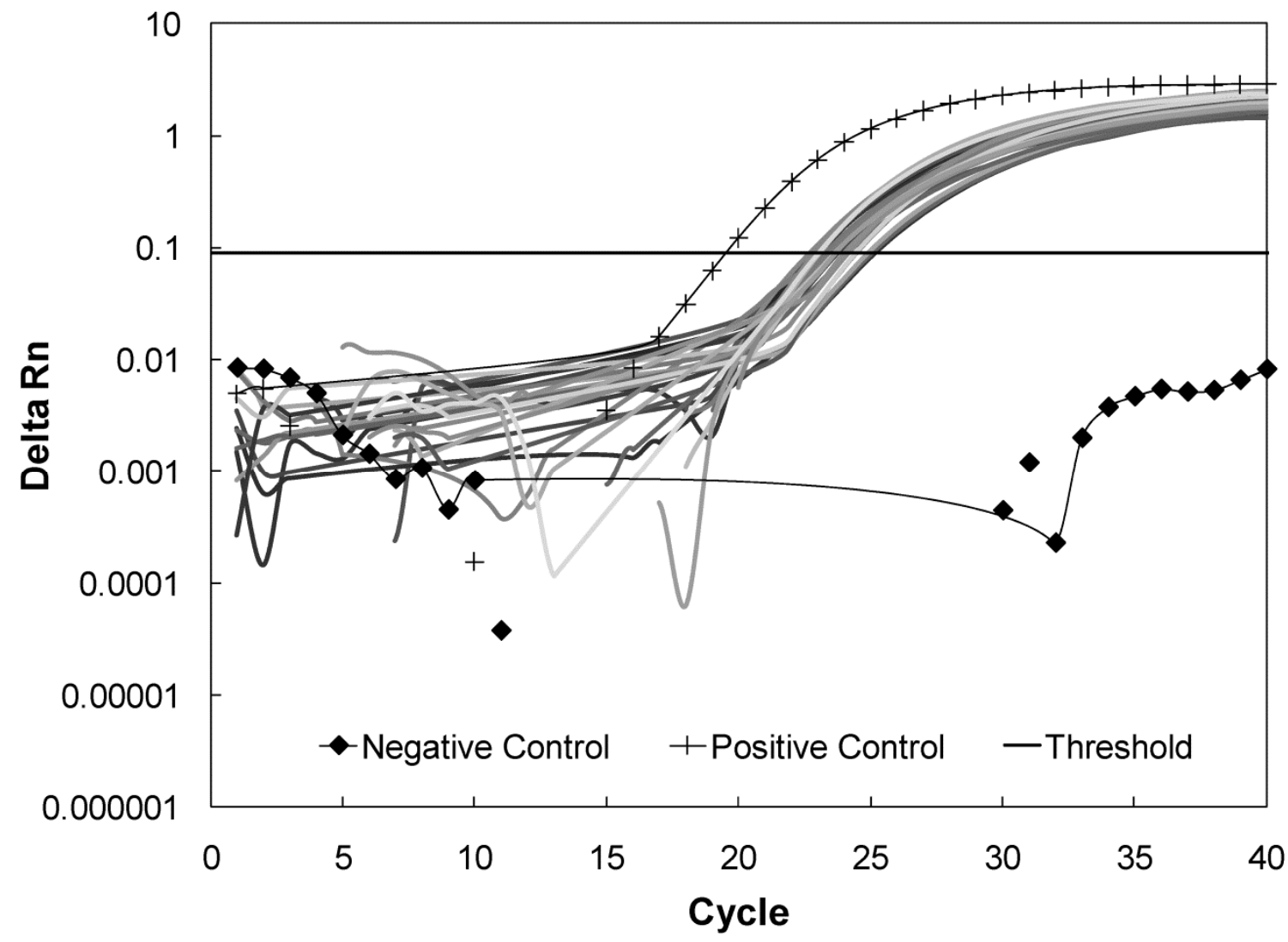

Fig. 4. Amplification plot of Heterodera glycines genomic DNA with SYBR Green real-time quantitative polymerase chain reaction (qPCR) and a primer pair designed to amplify the nematode HgSNO gene from infected roots of cultivar Lee 74 and cultivar Peking (PI 548402) $24 \mathrm{~h}$ postinfestation with 1,000 $\mathrm{H}$. glycines second-stage juveniles $/ \mathrm{ml}$ of distilled water per seedling. Distilled water was used in place of DNA as a negative control and $7.8 \mathrm{ng} / \mathrm{\mu l} \mathrm{H}$. glycines gDNA was used as a positive control. 
7-day-old inoculum was composed of dead or starving nematodes, causing poor infection. Lambert et al. (18) designed a sand column for the purpose of cleaning and surface-sterilizing nematodes by allowing them to crawl through the sand and be collected in sterile distilled water. Active $\mathrm{J} 2$ will crawl through the sand column in about $12 \mathrm{~h}$. Less viable $\mathrm{J} 2$ are retained in this sand biofilter, and the remaining $\mathrm{J} 2$ are highly infective.

To detect, amplify, and quantify $H$. glycines gDNA in infected roots, we first validated the qPCR assay by checking the efficiency of the primer pairs used and by testing for PCR inhibition. Livak and Schmittgen (20) reported that the sensitivity and efficiency of the primers can be assessed by observing how $\mathrm{Ct}$ values vary with each dilution. Bessetti (5) reported that soil and plant material may contain PCR inhibitors, and Malvick and Impullitti (24) expressed how critical it is to test for PCR inhibitors and account for them in qPCR assays. To our knowledge, this is the first report on detection and quantification of $H$. glycines gDNA in infected roots.

As nematodes develop inside infected soybean roots, their gDNA content increases. However, in incompatible hosts such as Peking, nematodes rarely reach the $\mathrm{J} 3$ stage, and no adults are observed (11). H. glycines $\mathbf{J} 2$ generally penetrate roots of soybean irrespective of the level of resistance $(12,13)$. Syncytia are initiated

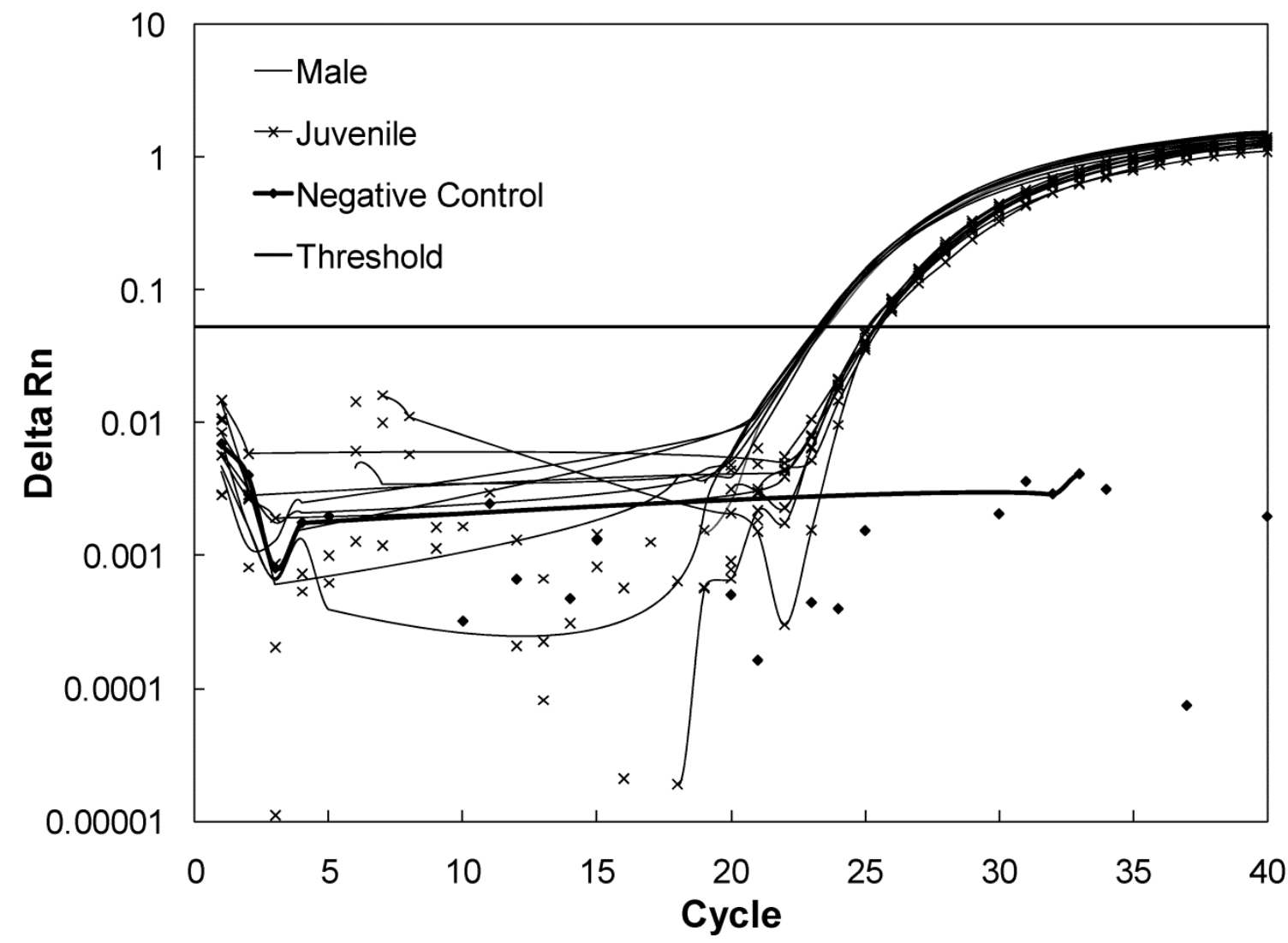

Fig. 5. Real-time quantitative polymerase chain reaction (qPCR) amplification plots of genomic DNA of Heterodera glycines males and juveniles amplified with SYBR Green real-time quantitative polymerase chain reaction (qPCR) and a primer pair designed to amplify the HgSNO gene. Distilled water was used as a negative control.

Table 5. Mean comparisons of real-time quantitative polymerase chain reaction (qPCR) cycle threshold (Ct) values for Heterodera glycines genomic DNA content in cultivar Lee 74 and cultivar Peking (PI 548402) at 1, 7, 10,14, and 21 days postinfestation (dpi)

\begin{tabular}{|c|c|c|c|c|c|c|c|}
\hline \multirow[b]{2}{*}{ Experiment $^{\mathbf{b}}$} & \multirow[b]{2}{*}{ dpi } & \multicolumn{2}{|c|}{ Average qPCR Ct value ${ }^{a}$} & \multirow[b]{2}{*}{$\mathbf{S D}^{\mathbf{c}}$} & \multirow[b]{2}{*}{$\Delta \mathbf{C t}$} & \multirow[b]{2}{*}{$2^{-\Delta C t d}$} & \multirow[b]{2}{*}{$P$} \\
\hline & & Lee 74 & Peking & & & & \\
\hline \multicolumn{8}{|l|}{1} \\
\hline & 1 & 23.57 & 23.61 & 0.448 & 0.04 & 1.03 & 0.935 \\
\hline & 7 & 21.47 & 22.12 & 0.484 & 0.65 & 1.57 & 0.215 \\
\hline & 10 & 19.00 & 20.07 & 0.289 & 1.07 & 2.10 & 0.006 \\
\hline & 14 & 23.74 & 26.31 & 1.829 & 2.57 & 5.94 & 0.198 \\
\hline & 21 & 24.66 & 29.81 & 0.468 & 5.15 & 35.51 & $<0.001$ \\
\hline \multicolumn{8}{|r|}{-0.001} \\
\hline & 1 & 23.26 & 23.30 & 0.315 & 0.04 & 1.03 & 0.907 \\
\hline & 7 & 21.80 & 22.99 & 0.433 & 1.19 & 2.28 & 0.025 \\
\hline & 10 & 21.34 & 22.88 & 0.296 & 1.54 & 2.91 & 0.001 \\
\hline & 14 & 19.97 & 20.40 & 0.211 & 0.43 & 1.35 & 0.081 \\
\hline & 21 & 20.25 & 23.82 & 0.888 & 3.57 & 11.88 & 0.007 \\
\hline
\end{tabular}

\footnotetext{
${ }^{a}$ H. glycines genomic DNA (gDNA) content in infected Lee 74 and Peking (PI 548402) was determined with SYBR Green with a primer pair designed to amplify the $\mathrm{HgSNO}$ gene in real-time quantitative polymerase chain reaction $(\mathrm{qPCR})$. Cycle threshold $(\mathrm{Ct})$ values were averaged. $\mathrm{Ct}=\mathrm{threshold}$ cycle number when fluorescence of the sample exceeded background fluorescence.

${ }^{\mathrm{b}}$ In each experiment, five seedlings of cultivars Lee 74 and Peking (PI 548402) were infested with 1,000 H. glycines second-stage juveniles/ml of distilled water per seedling.

${ }^{\mathrm{c}} \mathrm{SD}=$ standard deviation.

d $2^{-\Delta C t}$, represents the fold difference in H. glycines gDNA content between cultivars Lee 74 and Peking (PI 548402).
} 
Table 6. Probability and $F$ values for single degree of freedom mean comparisons of different soybean cultivars to penetration and development of Heterodera glycines 7, 10, 14, and 21 days postinfestation (dpi) with SYBR Green real-time qPCR

\begin{tabular}{|c|c|c|c|c|c|}
\hline \multirow[b]{2}{*}{ dpi } & \multirow[b]{2}{*}{ Single df contrast } & \multicolumn{2}{|c|}{ Experiment 1} & \multicolumn{2}{|c|}{ Experiment 2} \\
\hline & & $F$ value & $P$ & $F$ value & $P$ \\
\hline \multicolumn{6}{|l|}{7} \\
\hline & Lee 74 vs. HR & 10.54 & 0.004 & 5.390 & 0.031 \\
\hline & Lee 74 vs. MR & 0.38 & 0.543 & 0.650 & 0.430 \\
\hline & Lee 74 vs. S & 3.02 & 0.098 & 0.020 & 0.892 \\
\hline & HR vs. MR & 13.81 & 0.001 & 19.57 & $<0.001$ \\
\hline & MR vs. S & 11.11 & 0.003 & 0.890 & 0.356 \\
\hline & HR vs. S & 49.68 & $<0.001$ & 12.10 & 0.002 \\
\hline \multicolumn{6}{|l|}{10} \\
\hline & Lee 74 vs. HR & 28.94 & $<0.001$ & 56.45 & $<.001$ \\
\hline & Lee 74 vs. MR & 13.97 & 0.001 & 33.27 & $<.001$ \\
\hline & Lee 74 vs. S & 4.44 & 0.048 & 9.18 & 0.007 \\
\hline & HR vs. MR & 5.39 & 0.031 & 6.09 & 0.023 \\
\hline & MR vs. S & 5.32 & 0.032 & 14.99 & 0.001 \\
\hline & HR vs. S & 21.42 & $<0.001$ & 40.19 & $<.001$ \\
\hline \multicolumn{5}{|l|}{14} & 0.138 \\
\hline & Lee 74 vs. MR & $\begin{array}{l}25.11 \\
15.05\end{array}$ & $\begin{array}{r}<0.001 \\
0.001\end{array}$ & $\begin{array}{l}2.59 \\
0.04\end{array}$ & $\begin{array}{l}0.158 \\
0.835\end{array}$ \\
\hline & Lee 74 vs. S & 0.03 & 0.876 & 0.01 & 0.934 \\
\hline & HR vs. MR & 1.72 & 0.205 & 3.57 & 0.073 \\
\hline & MR vs. S & 32.62 & $<0.001$ & 0.03 & 0.859 \\
\hline & HR vs. S & 49.31 & $<0.001$ & 4.28 & 0.052 \\
\hline \multicolumn{6}{|l|}{21} \\
\hline & Lee 74 vs. HR & 40.61 & $<0.001$ & 26.38 & $<0.001$ \\
\hline & Lee 74 vs. MR & 33.85 & $<0.001$ & 24.54 & $<0.001$ \\
\hline & Lee 74 vs. S & 2.99 & 0.099 & 0.010 & 0.913 \\
\hline & HR vs. MR & 0.61 & 0.442 & 0.070 & 0.798 \\
\hline & MR vs. S & 33.45 & $<0.001$ & 46.90 & $<0.001$ \\
\hline & HR vs. S & 43.13 & $<0.001$ & 50.51 & $<0.001$ \\
\hline
\end{tabular}

and formed in both compatible and incompatible hosts within 2 dpi $(11,30)$. At this point, there is no difference between syncyntia formed in resistant cultivar Peking and the ones observed in Lee (14). Riggs et al. (30) showed that at 4 dpi, syncytia in Peking start deteriorating, but only at $7 \mathrm{dpi}$ was a remarkable degeneration of the feeding site observed. Therefore, consistent differences in nematode gDNA content between incompatible and compatible hosts could not be detected at 7 dpi.

Endo (10) and Lauritis et al. (19) reported development of $H$. glycines in susceptible soybean plants and showed the presence of fully developed males inside the roots by $10 \mathrm{dpi}$. At this time, compatible (susceptible) soybeans contained more $H$. glycines gDNA than any soybean cultivar with some degree of resistance to $\mathrm{SCN}$, and consistent differences in gDNA content between incompatible and compatible hosts could be detected due to the presence of males.

At $14 \mathrm{dpi}$, difference in gDNA content between incompatible and compatible hosts was inconsistent. Colgrove and Niblack (7) demonstrated that the female-male ratio in compatible host Lee 74 is $1: 1$. Therefore, between 11 and $15 \mathrm{dpi}$, half of the population of nematodes (males containing four times more gDNA than J2) emerged from the roots to complete their reproductive life cycle. However, gDNA of dead nematodes (males and females) within the incompatible host was still detected and quantified.

Our study indicates that out of five different harvest points $(1,7,10$, 14 , and $21 \mathrm{dpi}$ ), it is by $10 \mathrm{dpi}$ that we can detect lower $\mathrm{H}$. glycines gDNA content in a resistant relative to a susceptible cultivar. This is consistent with previous histological and ultrastructural studies $(7,10$ $13,19,30)$. With the proposed qPCR assay, we were able to reduce the time to detect difference between soybean cultivars by at least 20 days compared with the traditional FI-based screening.

\section{Acknowledgments}

We thank Alison Colgrove and Ursula Reuter-Carlson for helping with DNA extraction and qPCR assay. This research was supported by the Illinois Soybean Association (ISA).

\section{Literature Cited}

1. Acedo, J. R., and Dropkin, V. H. 1982. Technique for obtaining eggs and juveniles of Heterodera glycines. J. Nematol. 14:418-420.
2. Acedo, J. R., Dropkin, V. H., and Luedders, V. D. 1984. Nematode population attrition and histopathology of Heterodera glycines-soybean associations. J. Nematol. 16:48-57.

3. Agudelo, P., Lewis, S. A., and Fortnum, B. A. 2011. Validation of a realtime polymerase chain reaction assay for the identification of Meloidogyne arenaria. Plant Dis. 95:835-838.

4. Berdal, K. G., and Holst-Jensen, A. 2001. RoundupReady® soybean eventspecific real-time quantitative PCR assay and estimation of the practical detection and quantification limits in GMO analyses. Eur. Food Res. Tech. 213:432-438.

5. Bessetti, J. 2007. An introduction to PCR inhibition. Profiles in DNA. Promega ${ }^{\circledR}$ Corporation.

6. Byrd, D. W., Jr., Kirkpatrick, T., and Barker, K. R. 1983. An improved technique for clearing and staining plant tissues for detection of nematodes. J. Nematol. 15:142-143.

7. Colgrove, A. L., and Niblack, T. L. 2005. The differential effect of resistan soybean on adult sex ratios of Heterodera glycines. J. Nematol. 37:161-167.

8. Colgrove, A. L., and Niblack, T. L. 2008. Correlation of female indices from virulence assays on inbred lines and field populations of Heterodera glycines. J. Nematol. 40:39-45.

9. Craig, J. P., Bekal, S., Hudson, M., Domier, L., Niblack, T. L., and Lambert, K. N. 2008. Analysis of a horizontally transferred pathway involved in vitamin B-6 biosynthesis from the soybean cyst nematode Heterodera glycines. Mol. Biol. Evol. 25:2085-2098.

10. Endo, B. Y. 1964. Penetration and development of Heterodera glycines in soybean roots and related anatomical changes. Phytopathology 54:79-88.

11. Endo, B. Y. 1965. Histological responses of resistant and susceptible soybean varieties, and backcross progeny to entry and development of Heterodera glycines. Phytopathology 55:375-381.

12. Endo, B. Y. 1991. Ultrastructure of initial responses of susceptible and resistant soybean roots to infection by Heterodera glycines. Rev. Nematol. 14: 73-94.

13. Endo, B. Y., and Veech, J. A. 1970. Morphology and histochemistry of soybean roots infected with Heterodera glycines. Phytopathology 60:14931498.

14. Gipson, I., Kim, K. S., and Riggs, R. D. 1971. An ultrastructural study of syncyntium development in soybean roots infected with Heterodera glycines. Phytopathology 61:347-353.

15. Halbrendt, J. M., and Dropkin, V. L. 1986. Heterodera glycines-soybean association: A rapid assay using pruned seedlings. J. Nematol. 18:370-374.

16. Hooper, J. D. 1986. Extraction of free-living stages from soil. Pages 5-30 in: Laboratory Methods for Work with Plant and Soil Nematodes. Ref. book 402. J. F. Southey, ed. Ministry of Agriculture, Fisheries, and Food, London.

17. Kim, K. S., and Riggs, R. D. 1992. Cytopathological reactions of resistant 
soybean plants to nematode invasion. Pages 157-168 in: Biology and Management of the Soybean Cyst Nematode. J. A. Wrather and R. D. Riggs, eds. American Phytopathological Society, St. Paul, MN.

18. Lambert, K. N., Ferrie, B. J., Nombela, G., Brenner, E. D., and Williamson, V. M. 1999. Identification of genes whose transcripts accumulate rapidly in tomato after root-knot nematode infection. Physiol. Mol. Plant Pathol. 55:341-348.

19. Lauritis, J. A., Rebois, R. V., and Graney, L. S. 1983. Development of Heterodera glycines Ichinohe on soybean, Glycine $\max$ (L.) Merr., under gnotobiotic conditions. J. Nematol. 15:272-280.

20. Livak, K. J., and Schmittgen, T. D. 2001. Analysis of relative gene expression data using real-time quantitative PCR and the 2(Delta Delta C(T)) method. Methods 25:402-408.

21. Madani, M., Subbotin, S. A., and Moens, M. 2005. Quantitative detection of the potato cyst nematode, Globodera pallida, and the beet cyst nematode, Heterodera schachtii, using Real-Time PCR with SYBR green I dye. Mol. Cellular Probes 19:81-86.

22. Mahalingam, R., Knap, H. T., and Lewis, S. A. 1998. Inoculation method for studying early responses of Glycine max to Heterodera glycines. J. Nematol. 30:237-240.

23. Malvick, D. K., and Grunden, E. 2005. Isolation of fungal DNA from plant tissues and removal of DNA amplification inhibitors. Mol. Ecol. Notes 5:958-960.

24. Malvick, D. K., and Impullitti, A. E. 2007. Detection and quantification of Phialophora gregata in soybean and soil samples with a quantitative, realtime PCR assay. Plant Dis. 91:736-742.

25. Mekete, T., Reynolds, K., Lopez-Nicora, H. D., Gray, M. E., and Niblack, T. L. 2011. Distribution and diversity of root-lesion nematode (Pratylenchus spp.) associated with Miscanthus $\times$ giganteus and Panicum virgatum used for biofuels, and species identification in a multiplex polymerase chain reaction. Nematology 13(6):673-686.
26. Melton, T. A., Jacobsen, B. A., and Noel, G. R. 1986. Effects of temperature on development of Heterodera glycines on Glycine max and Phaseolus vulgaris. J. Nematol. 18:468-474.

27. Niblack, T. L. 2005. Soybean cyst nematode management reconsidered. Plant Dis. 89:1020-1026.

28. Noel, G. R. 1992. History, distribution, and economics. Pages 1-14 in: Biology and Management of the Soybean Cyst Nematode. R. D. Riggs and J. A. Wrather, eds. American Phytopathological Society, St. Paul, MN.

29. Noel, G. R. 2004. Soybean response to infection. Pages 131-154 in: Biology and Management of Soybean Cyst Nematode, 2nd ed. D. P. Schmitt, J. A. Wrather, and R. D. Riggs, eds. Schmitt and Associates of Marceline, Marceline, MO.

30. Riggs, R. D., Kim, K. S., and Gipson, I. 1973. Ultrastructural changes in Peking soybean infected with Heterodera glycines. Phytopathology 63:7684.

31. Shannon, J. G., Arelli, P. R., and Young, L. D. 2004. Breeding for resistance and tolerance. Pages 155-175 in: Biology and Management of Soybean Cyst Nematode, 2nd ed. D. P. Schmitt, J. A. Wrather, and R. D. Riggs, eds. Schmitt and Associates of Marceline, Marceline, MO.

32. Subbotin, S. A., Peng, D., and Moens, M. 2001. A rapid method for the identification of the soybean cyst nematode Heterodera glycines using duplex PCR. Nematology 3:365-371.

33. Wang, J., Niblack, T. L., Tremain, J. A., Wiebold, W. J., Tylka, G. L., Marrett, C. C., Noel, G. R., Myers, O., and Schmidt, M. E. 2003. Soybean cyst reduces soybean yield without causing obvious aboveground symptoms. Plant Dis. 87:623-628.

34. Wrather, J. A., and Koenning, S. R. 2009. Effects of disease on soybean yields in the United States 1996 to 2007. Online. Plant Health Progress doi: 10.1094/PHP-2009-0401-01-RS

35. Young, L. D. 1996. Yield loss in soybean caused by Heterodera glycines. J. Nematol. Suppl. 28:604-607.

On 23 October 2012, in the Literature Cited section, number 25 was corrected by deleting an incorrect citation and inserting the correct one. 